УДК 621.387.143:662.76

doi: $10.18101 / 2306-2363-2017-2-3-75-82$

\title{
ГАЗИФИКАЦИЯ ДРЕВЕСИНЫ С ПОСЛЕДУЮЩЕЙ ВЫРАБОТКОЙ ЭЛЕКТРИЧЕСКОЙ ЭНЕРГИИ
}

\section{(С) С. Ю. Шишулькин}

кандидат технических наук, доцент,

Бурятский государственный университет

Россия, 670000, ул. Смолина, 24а

E-mail: voin-spec@yandex.ru

\section{(C) С. Л. Буянтуев}

доктор технических наук, профессор,

Восточно-Сибирский государственный университет технологий и управления

Россия, 670031, Улан-Удэ, ул. Ключевская, 40в

E-mail: buyantuevsl@mail.ru

\section{(ㄷ) И. В. Старинский}

кандидат технических наук,

Восточно-Сибирский государственный университет технологий и управления

Россия, 670031, Улан-Удэ, ул. Ключевская, 40в

Приведены результаты исследований работы газификатора древесины, процессов, протекающие в нем и последующего использования, полученного генераторного газа для выработки электрической энергии. Для исследования процессов газификации древесины был создан газификатор обращенного процесса газификации, содержащий устройства очистки получаемого газа от золы, влаги и смол. В ходе исследования режимов работы газификатора проведены эксперименты по получению генераторного газа, определен состав получаемого газа. В статье описано устройство и принцип работы газификатора, а также подготовка топлива к газификации, его состав и тип. Исследования показали применимость данного газификатора для выработки электроэнергии путем сжигания генераторного газа в бензиновых электростанциях, что может быть полезным в отдаленных районах, не обладающих развитой энергосистемой. В качестве топлива для газификатора могут быть применены сучья и ветки, остающиеся после вырубки деревьев.

Ключевые слова: газификатор, газогенератор, генераторный газ, электрогенератор, газификация, древесина, древесные угли.

Газификаторы древесины получили широкое распространение в прошлом столетии. В основном данные газификаторы использовались для выработки генераторного газа, который сжигался в двигателях внутреннего сгорания легковых и грузовых автомобилей.

В автомобилях оборудованных газогенераторными установками в качестве топлива применяли различные породы древесины, а в некоторых применяли и уголь. Газификацию проводили в газификаторах, установленных как непосредственно на автомобиле, так и на прицепе.

Первые газогенераторные автомобили на территории Советского союза появились еще в 20-х гг. прошлого столетия. Их применение было обусловлено низким уровнем добычи жидких топлив, а также широким распростра- 
нением твердых топлив (уголь, древесина) в отдаленных районах, куда завозить жидкое топливо было экономически невыгодно. Поставка нефтяного топлива в такие районы требовало значительных затрат и создавало значительные нагрузки на транспортную систему.

Так, например, для перевозки 1 т бензина на расстояние 6000 км затрачивается транспортная работа 6000 т•км, в то время как полезная работа, совершаемая автомобилями на 1 т перевезенного бензина, равна всего лишь 5400 т•км при средних эксплуатационных показателях.

Цель исследования - разработка и создание газогенератора в соответствии с рабочими параметрами бензинового электрогенератора.

Материалы, методы и исследования

Авторами исследований разработаны ряд установок [1-4] для газификации углей и древесины. На начальном этапе стояла задача создания компактного и мобильного газификатора оптимальной, с точки зрения трудоемкости изготовления и эффективности тепловых процессов газификации древесины, конструкции. Для этого были применены расчетные методы с последующей разработкой проектной документации, в том числе и чертежей установки (рис. 1). На основании проектной документации в лаборатории физики плазмы и плазменных технологий был изготовлен газификатор BSW-2 (рис. 2).
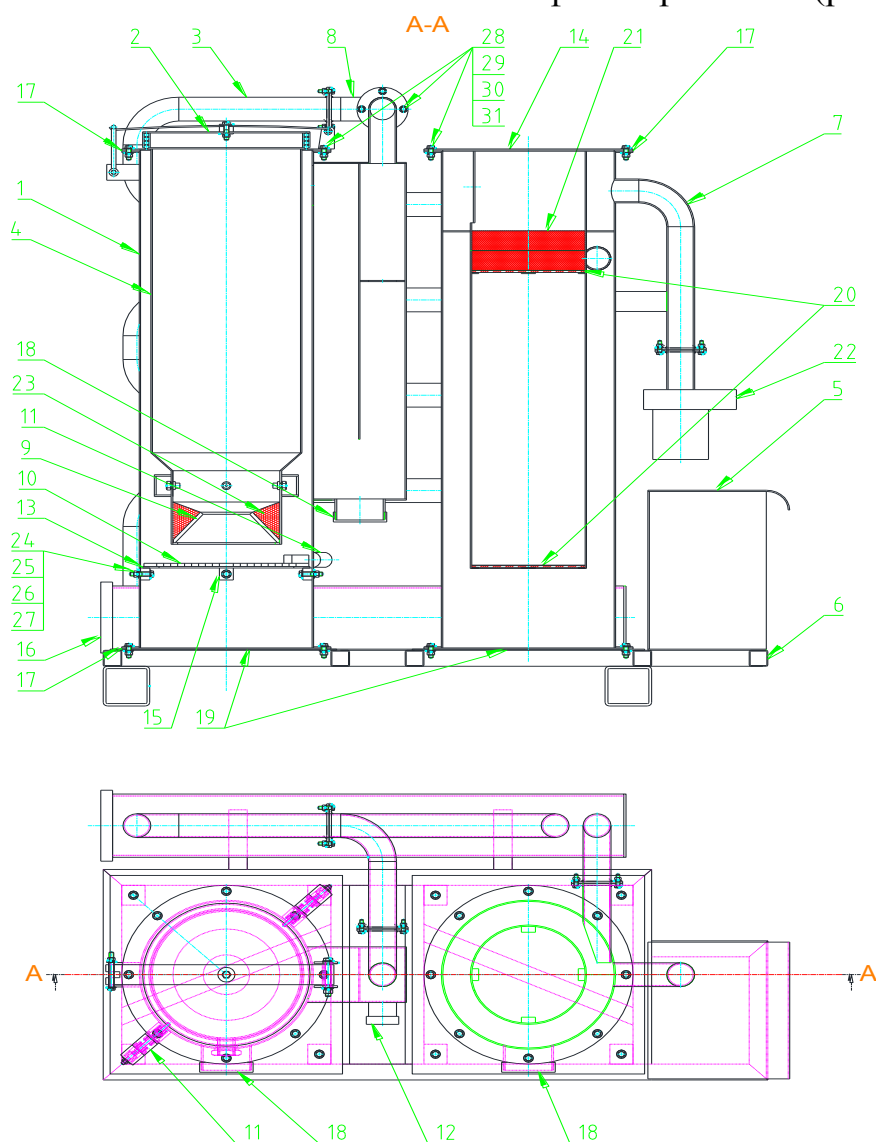

Рис. 1. Сборочный чертеж газификатора BSW-2 
Спроектированный газификатор представляет собой газификатор обращенного процесса газификации, устройство которого представлено на рис. 1. В газификаторах этого типа воздух подается в среднюю по их высоте часть, в которой и происходит процесс горения. Отбор образовавшихся газов осуществляется ниже подвода воздуха. Активная зона занимает часть газогенератора от места подвода воздуха до колосниковой решетки, ниже которой был расположен зольник с газоотборным патрубком. Так в разработанном газификаторе воздух вводится на 1/3 от высоты газификатора (выше зоны $23)$, где происходит горение топлива. В таком случае активная зона занимает промежуток между вводом воздуха и колосниковой решеткой 10 , размещенной на опорах 13 и 15, и оборудована автоматическим приводом решетки 11 для сброса излишков золы в зольник 18. Отвод генераторного газа из газификатора осуществляют в верхней части. Так газ из реакционной зоны 9 проходит сквозь золу и поднимается вверх по кольцевому зазору между топливным бункером 4 и корпусом 1 газификатора, соединенныхмежду собой посредством креплений 17, 28-31. Отведенный газ попадает в золоуловитель 12 , откуда по трубе 8 подается в охладитель 3 , где газ охлаждается и выделившаяся при газификации древесины влага и смолы конденсируются и собираются в конденсатосборнике 16. После кондесатосборника генераторный газ тангенциально вводится в циклон 14 тонкой очистки. Внутри циклона 14 установлена внутренняя труба 20 с решетками, на верхней решетке уложена базальтовая вата 21. Из верхней части циклона 14 газ по трубе 7 выводится с помощью вытяжного вентилятора 22 и подается в смесительное устройство и далее во впускной коллектор двигателя внутреннего сгорания (на рисунке не показано). Загрузка топлива производится в топливный бункер 4 через загрузочный люк 2. Удаление золы осуществляется из зольника 18. Вся конструкция смонтирована на раме 6 , которая был доработана и имеет в нижней части колеса (рис. 2) для удобства перемещения газификатора.

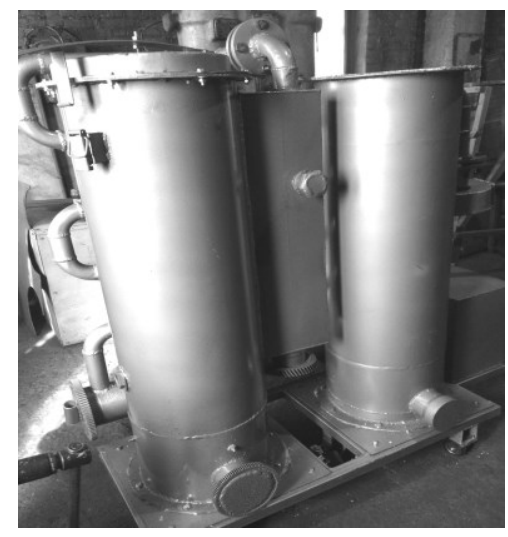

Рис. 2. Газификатор BSW-2

Для снижения потерь тепла в окружающую среду и предотвращения тепловых травм обслуживающего персонала газификатор имеет теплоизолирующий внешний слой (на рисунках не показан). Еще одна задача, которую 
позволяет решить наружная теплоизоляция является создание более высоких температур в топливном бункере. Достигается это за счет проходящего с внешней стороны горячего генераторного газа, который отдает свое тепло топливному бункеру, нагревая его. Под действием данного тепла подсушка топлива начинается намного раньше, чем в газификаторах прямого и поперечного типов. За счет этого происходит увеличение зон сухой перегонки и подсушки древесины, которые расположены выше активной зоны в топливном бункере. Выделяющиеся при подсушке и перегонке древесины влага топлива и смолы не могут пройти мимо активной зоны газификатора. При прохождении через данную зону, обладающую высокой температурой, продукты сухой перегонки подвергаются частичному сгоранию и разложению, в результате чего количество смол в выходящем из газификатора газе снижается до минимальных значений.

Часто на практике получаемые при генерации генераторного газа из угля и древесины влага и смолы, последние из которых не успевают разложиться, смешиваются с генераторным газом, выходящим из активной зоны, и вместе с ним отсасываются через газоотборный патрубок. Большая загрязненность генераторного газа смолами делает его непригодным для его сжигания в ДВС, так как при дальнейшем снижении температуры генераторного газа смолы конденсируются в газопроводах, во впускном коллекторе и на клапанах двигателя, и выводя его из строя. Поэтому при производстве генераторного газа следует уделять особое внимание очистке газа от данных примесей не только химическим способом, но и с помощью механических устройств. Для этого в представленном газогенераторе были дополнительно введены в конструкцию золоуловитель, охладитель генераторного газа и циклон.

Если нагревать топливо в безвоздушном пространстве и без подвода кислорода (как это происходит в топливном бункере 4), то в первую очередь из топлива начнет испаряться влага. По мере прогрева начнется выход горючих компонентов. По большому счету эти компоненты состоят из соединений углерода с кислородом и водородом. В основном генераторный газ, полученный без доступа воздуха содержит оксид углерода $(\mathrm{CO})$, диоксид углерода $\left(\mathrm{CO}_{2}\right)$ и непредельные углеводороды представленные $\mathrm{CH}_{4}$ и $\mathrm{C}_{\mathrm{n}} \mathrm{H}_{\mathrm{m}}$, а также в виде смол и других веществ. Из чего можно заключить, что при сухой перегонке без доступа воздуха основное количество углерода остается в топливе, а точнее в коксе.

Как известно газификация представляет собой процесс образования горючего газа путем окисления углерода твердого топлива кислородом воздуха и/или водяным паром.

При газификации в слое протекают две основные реакции, а именно образование диоксида и оксида углерода. В первом случае происходит процесс полного сгорания углерода с образованием инертного углекислого газа $\mathrm{CO}_{2}$. Полученное тепло в результате этой экзотермической реакции составляет 97650 ккал/моль. Во втором случае в результате неполного окисления углерода образуется горючий газ - окись углерода СО и выделяется соответственно меньшее количество тепла (29430 ккал/моль). Если же в газификаторе существует избыток кислорода и тепла диоксид углерода вступает в 
дальнейшие реакции и происходит его восстановление до СО. Такая реакция является эндотермической и протекает с поглощением тепла.

При газификации древесины получается генераторный газ, в состав которого входят горючие компоненты и балласт. К последнему можно отнести азот, смолы и уксусную кислоту. Данные смолы и кислота вредны как для самого двигателя, так и для вспомогательного оборудования и трубопроводов. Но, не смотря на эти недостатки, древесина является прекрасным топливом для газификаторов.

При воздушной газификации генераторный газ будет содержать в самом лучшем случае не более $34,7 \%$ СО. Калорийность такого газа составит максимум 1048 ккал/м ${ }^{3}$. В реальных условиях идеальные процессы равновесия недостижимы, равновесие системы $\mathrm{C}+\mathrm{CO}_{2}=2 \mathrm{CO}$ не успевает установиться, и количество окиси углерода в генераторном газе бывает намного ниже расчетных.

В реальных условиях в древесине всегда присутствует влага, и при загрузке топлива она поступает в газификатор. Поэтому в газификаторах древесины всегда протекает процесс паровоздушной газификации. При подсушке топлива влага переходит в парообразное состояние и вместе с образующейся при сухой перегонке химической влагой в сумме составляет воду, участвующую в процессе газификации, а часть уносится с газом. Часто в газогенераторах протекает и процесс окисления окиси углерода водяным паром. Данная реакция является экзотермической и протекает с выделением незначительного тепла порядка 9849 ккал/моль.

Установить точно зону разделения между зонами горения и восстановления на практике не представляется возможным, и восстановительные процессы, скорее всего, начинаются еще в зоне горения. В связи, с чем обе эти зоны при практическом рассмотрении процессов газификации объединяются в одну зону носящую название активной зоны газификации или активного слоя топлива. В данной зоне протекают все вышеуказанные реакции. На выходе из активного слоя мы получаем генераторный газ, основными компонентами которого являются диоксид углерода, окись углерода, водород и азот.

В качестве исходного топлива была использована сосна со следующим соотношением горючих компонентов в органической массе древесины (в \% по мacce):
углерода......... 48,7;
водорода.........6,3;
кислорода.......43,4;
азота..............1,0.

Низшая теплотворность способность древесины в среднем составляет порядка 4500 ккал/кг (при исследовании не определялась). Зольность сухой древесины в зависимости от породы изменяется от 0,4 до 1\%. Влажность древесины составила в среднем $37 \%$.

При изучении зольного остатка, полученного при газификации, установлено, что отсутствует его оплавление и спекание, т. е. он не расплавляется. Отсутствует и ошлаковывание колосниковых решеток, что не затрудняет движение генераторного газа, и как следствие способствует низкому аэродинамическому сопротивлению. Образовавшийся зольный остаток необходим 
для получения генераторного газа более высокого качества. Связано это с тем, что сырой газ при прохождении через угли очищается от вредных компонентов, за счет их разложения и частичного поглощения, а также выхода значительной доли углерода с образованием горючих компонентов. Кроме того, древесный уголь позволяет уменьшить высоту слоя необходимого для эффективного производства генераторного газа. Так как одним из основных условий, влияющих на качество получаемых древесных углей является размер исходного сырья и его однородность, то для газификации было решено использовать куски древесины с размером по длине 40-50 мм, и высоте 40-60 мм. Применение мягких сортов древесины (например, ель, кедр и др.), а также газификация мелких кусков приводит к образованию непрочных древесных углей, при разрушении которых происходит нарушение аэродинамического сопротивления, затрудняющего проход генераторного газа и как следствие более частую очистку газификатора.

Соотношение между горючими компонентами и количеством балласта в генераторном газе также зависят от количества воды, участвующей в процессе газификации, летучих в топливе и от режима самой газификации.

Отрицательно на работу газификатора оказывает обратная реакция восстановления углекислого газа $2 \mathrm{CO} \rightarrow \mathrm{CO}_{2}+\mathrm{C}$. В результате концентрация оксида углерода в генераторном газе снижается в среднем на 27\%. В газификаторе на древесном угле снижении концентрации окиси углерода обусловлено смешением краевого газа и основного газового потока. В связи с тем, что вблизи стенок реакции смешения топлива и воздушного потока затруднены, в данной области существует дефицит окислительного агента и как следствие образуется генераторный газ плохого качества.

В полученном генераторном газе помимо горючих компонентов $\left(\mathrm{CO}, \mathrm{H}_{2}\right.$, $\left.\mathrm{CH}_{4}, \mathrm{C}_{\mathrm{n}} \mathrm{H}_{\mathrm{m}}\right)$ и балласта $\left(\mathrm{CO}_{2}, \mathrm{~N}_{2}, \mathrm{H}_{2} \mathrm{O}\right)$ содержится пыль, состоящая из золы и сажи. Отбор газа проводился из золоуловителя 12 (рис. 1). Золой и сажей генераторный газ загрязняется при прохождении через уголь и зольник 18. Усредненный состав генераторного газа приведен в табл.

Таблица

Состав генераторного газа

\begin{tabular}{|c|c|c|c|c|c|c|}
\hline $\mathrm{H}_{2}$ & $\mathrm{CO}_{2}$ & $\mathrm{CO}$ & $\mathrm{CH}_{4}$ & $\mathrm{C}_{\mathrm{n}} \mathrm{H}_{\mathrm{m}}$ & $\mathrm{O}_{2}$ & $\mathrm{~N}_{2}$ \\
\hline 15,9 & 8,9 & 21,0 & 2,3 & 0,2 & 1,3 & 50,4 \\
\hline
\end{tabular}

Как видно из таблицы основными горючими компонентами являются оксид углерода и водород в сумме составляющие 39,4\%. Сумма всех горючих компонентов составляет 39,5\%. Так как в качестве окислительного агента при газификации древесины использовался воздух, то полученный генераторный газ сильно забалластирован азотом 50,4\%. Полученные результаты согласуются с литературным данными [5;6].

Пробные пуски бензиновой электростанции мощностью 3-5 кВт на данном генераторном газе показали устойчивую работу данной станции. В зависимости от электрической мощности вырабатываемой станцией полной загрузки газификатора хватало на 85-133 мин работы. После чего наблюдалось 
снижение объема производимого генераторного газа и как следствие нехватка мощности электростанции.

\title{
Выводы
}

Из полученных результатов по составу газа видно, горючий газ обладает достаточным количеством горючих компонентов для его использования в двигателях внутреннего сгорания. Выработка электроэнергии в бензиновой электростанции возможна без изменения конструкции последней. Необходимо лишь установить на входе в электростанцию смесительное устройство, которое будет смешивать генераторный газ с воздухом в необходимых пропорциях.

Разработанный газификатор может активно применятся для газификации ветвей и сучков, являющихся отходами заготовки леса. В условиях отсутствия источников электроэнергии данные газификаторы, совмещённые с электрогенераторами, являют альтернативным методом получения электроэнергии. Учитывая, что в качестве топлива применяется отходы лесозаготовок себестоимость вырабатываемой электроэнергии в сравнении с выработкой последней на бензине снижается в разы. Причем если учесть затраты на транспортировку бензина до места выработки электроэнергии эффект от использования отходов лесозаготовки станет более значительным.

\section{Литература}

1. Буянтуев С. Л., Зонхоев Г. Б., Шишулькин С. Ю., Старинский И. В. Плазменно-термическая переработка и подготовка углей к сжиганию в энергетике и жилищно-коммунальном хозяйстве. - Улан-Удэ: изд-во ВСГУТУ, 2014. - 164 с.

2. Буянтуев С. Л., Цыдыпов Д. Б., Доржиев А. Ц. и др. Двухступенчатый способ термической подготовки пылевидного топлива и установка для его осуществления. Патент РФ №2171431, от 27 июля 2001 г.

3. Буянтуев С. Л., Шишулькин С. Ю. Двухступенчатый способ термической подготовки кускового топлива к сжиганию и установка для его осуществления. Патент РФ №2366861 от 10 сентября 2009 г.

4. Буянтуев С. Л., Шишулькин С. Ю. Перспективы и проблемы использования газогенераторов угля для выработки тепловой энергии // Вестник ВСГТУ. - 2014. № 6. - C. $28-32$.

5. Токарев Г. Г. Газогенераторные автомобили. — М.: изд.-во «МАШГИЗ», 1955. $-207 \mathrm{c}$.

6. Белоусов Е. В. Использование твердых топлив в двигателях внутреннего сгорания // Проблемы создания новых машин и технологий: Научн. труды КГПИ. № 1(8). - Кременчуг: изд.-во КГПИ, 2000. — С. 420-422.

\section{GASIFICATION OF WOOD WITH SUBSEQUENT GENERATION \\ OF ELECTRICAL ENERGY}

\author{
S. Yu. Shishulkin \\ candidate of Technical Sciences, associate Professor, \\ Buryat State University \\ Russia, 670000, Smolina Str., 24a \\ E-mail: voin-spec@yandex.ru
}




\title{
S. L. Buyantuev
}

doctor of Technical Sciences, Professor,

East Siberia State University of Technology and Management

Russia, 670031, Ulan-Ude, Klyuchevskaya Str., 40b

E-mail: buyantuevsl@mail.ru

\author{
I. V. Starinsky \\ candidate of Technical Sciences, Senior Lecturer. \\ East Siberia State University of Technology and Management \\ Russia, 670031, Ulan-Ude, Klyuchevskaya Str., 40b
}

The article gives the results of research of the wood gasifier work, processes occurring in it and subsequent use of the generated gas for the production of electrical energy. To study wood gasification process the gasifier of reverse gasification process, containing devices to purify obtained gas from ash, moisture and resins was created. In the course of the study of the operating conditions of the gasifier experiments were conducted to obtain the generator gas, and composition of the produced gas was determined. The article describes the device and operating principle of the gasifier, as well as the preparation of fuel for gasification, its composition and type. Studies have shown the applicability of this gasifier for the production of electricity by burning the generator gas in gasoline electric generators, that can be useful in remote areas with no developed power system. As a fuel for a gasifier twigs and branches remainted after trees-felling can be used.

Keywords: gasifier, gas generator, generator gas, electric generator, gasification, wood, charcoal. 